\title{
E्दुreatidara
}

\section{A Culfura da Escola Prisional: entre o instituído e o instituinte}

Elizabeth de Lima Gil Vieira

RESUMO - A Cultura da Escola Prisional: entre o instituído e o instituinte. O presente trabalho intenciona conhecermos e refletirmos sobre o cotidiano e a cultura da escola da prisão. É também imprescindível conhecer os números que aludem ao sistema prisional brasileiro, ou seja, número e perfil dos encarcerados, visto que entendemos serem esses dados significativos para os estudos sobre a educação carcerária. Torna-se necessário desvendar as transformações possíveis que se (re)desenham em um lugar, a priori, marcado pelo controle, pela estaticidade, mas que, a partir de um olhar mais apurado às experiências ali vividas, pode ser visto como fecundo a partir das práticas cotidianas dos sujeitos que fazem a escola da prisão. Palavras-chave: Educação. Prisão. Cultura Escolar.

ABSTRACT - The Prison School Culture: between instituted and instituting. This paper intends to know and reflect on daily life and culture of the prison school. It is also essential to know the numbers that allude to the Brazilian prison system, number and profile of the prisoners, because we understand that these are important data for studies on education in prisons. It is necessary to unravel the possible transformations that (re)draw in a place, a priori, marked by the control, the static, but which, from a closer look at the experiences lived there, it can be seen as fruitful as daily practices of the subjects that make the prison school.

Keywords: Education. Prison. School Culture. 
Atestar a falência da pena de prisão, apontar a ineficiência do sistema penitenciário no que tange ao cumprimento dos paradoxais objetivos de punir e ressocializar, informar o número crescente de encarcerados em nosso país, parece simplesmente evidenciar o já sabido por todos. Entretanto, faz-se mister, ainda assim, refletirmos sobre a prisão (por muitos entendida como espaço de fracassos e fracassados, de excluídos e desacreditados) e, principalmente, sobre a escola na prisão (espaço de possibilidades e criatividade, apesar das marcas disciplinares que a constituem).

É preciso conhecer os números que aludem ao sistema prisional brasileiro, ou seja, número e perfil dos encarcerados, visto que entendemos serem esses dados significativos para, além de justificar a importância dos estudos sobre a prisão e a educação prisional, atestarem a necessidade de esforços de todos nós, cidadãos brasileiros, a fim de transformarmos, sem utopias, a realidade de muitos sujeitos privados de liberdade.

A estrutura do artigo pretende, então, apresentar ao menos uma parte dos resultados parciais da pesquisa, ainda não finalizada, cuja temática se encontra no cerne das discussões sobre a educação prisional. Inicio o trabalho situando o estudo, isto é, seus objetivos, relevância, questões e o contexto em que se insere. Em seguida, destaco brevemente alguns pressupostos teóricos em que se baseia, no contexto dos estudos da prisão, da escola e da cultura escolar. Por fim, evidencio algumas constatações desta investigação, sobre a cultura escolar prisional, a fim de que tragam subsídios e sirvam como contribuições para novas discussões no amplo cenário da educação carcerária e ainda para, quem sabe, suscitar novas questões.

A educação prisional se constitui como uma das assistências oferecidas ao preso pela Lei de Execução Penal' ${ }^{1}$. De acordo com o Artigo 11 da LEP as formas de assistência aos detentos são: "material à saúde, jurídica, educacional, social e religiosa" (Brasil, 1984, on-line). Em seu artigo 17, a LEP “[...] assegura que a assistência educacional compreenderá a instrução escolar e a formação profissional do preso e do internado [...]" (Brasil, 1984, on-line).

Embora, a educação nas prisões apresente interpretações e investimentos distintos de acordo com as políticas e interesses dos diversos estados, a partir do mês de junho de 2011 está em vigor, no Brasil, a Lei n. 12.433 garantidora da remissão da pena por estudo, um avanço na defesa dos direitos humanos e mais um instrumento para fortalecer a luta pela educação. Essa medida legal torna evidente e necessária uma melhoria na oferta, organização e qualidade na educação oferecida nos presídios. Até então, a LEP oferecia a remissão apenas pelo trabalho. A proporcionalidade estabelecida é a mesma referente ao trabalho (a cada doze horas de trabalho desconta-se um dia de pena), ou seja, a cada três dias de estudo, diminui-se um dia na pena, pois os dias de aula têm duração de quatro horas. Essa ação constitui importante avanço em rela-

94 Educação \& Realidade, Porto Alegre, v. 38, n. 1, p. 93-112, jan./mar. 2013. Disponível em: <http://www.ufrgs.br/edu_realidade> 
ção à educação prisional, mas ainda não garante investimentos e ações que possibilitem a todos participação efetiva em atividades educacionais oferecidas no espaço prisional. Fato esse constatado pelo baixo índice de presos que participam das atividades educacionais formais e informais oferecidas no sistema prisional brasileiro. De acordo com a coordenadora geral de Reintegração Social e Ensino, da Diretoria de Políticas Penitenciárias do Ministério da Justiça, Mara Fregapani, em um levantamento apresentado, apenas $8,3 \%$ dos presos participam das ações educativas nas prisões. Segundo ela, o Brasil possui Legislação, programas e verba, o que falta é “[...] gestão e políticas públicas eficientes [...]" (Relatoria Nacional para o Direito Humano à Educação, 2009).

Os dados da Relatoria Nacional para o Direito Humano à Educação (Relatoria Nacional para o Direito Humano à Educação, 2009) nos informam que $60 \%$ da população carcerária é formada por jovens entre 18 e 30 anos, e somente $12 \%$ possui o ensino fundamental, enquanto ínfimos 6\%, o Ensino Médio e que $6 \%$ desse pessoal se declara analfabeto. A partir de um entendimento prévio sobre a educação em presídios e o perfil de escolaridade dos detentos, é preciso, então, repensarmos a substituição do termo reinserção, evidenciado nos documentos oficiais sobre a função da prisão, por inserção.

O crescimento no número de encarcerados, no Brasil, é alarmante. A população carcerária do país, em 1990, contava com 90.000 presos. Em 2009, havia 473.622 pessoas cumprindo pena, sendo 174.372 em regime fechado (Sistema Penitenciário no Brasil, 2008). Em junho de 2011, de acordo com informações do DEPEN (Departamento Penitenciário Nacional), esse total chegou a 513.802 presos. Ou seja, um crescimento da população carcerária do Brasil de $471 \%$ em, aproximadamente, 20 anos. Em contrapartida, segundo dados do IBGE2, quase no mesmo período, de 1990 até 2010, o crescimento da população nacional foi de $30 \%$. O Brasil é hoje o terceiro país, no mundo, em número de encarcerados atrás apenas dos Estados Unidos e da China, respectivamente.

Em um primeiro momento, a partir de 1850, quando se deu o início do funcionamento oficial da Casa de Correção, no Rio de Janeiro, então capital do Império, o trabalho era o ponto forte das práticas prisionais. Depois, entre 1870 e 1880, a educação aparece como redentora daquele já cada vez mais numeroso grupo de desviantes.

Embora os discursos, que entendem a educação como aliada no processo de recuperação do apenado, façam eco junto a juristas, criminologistas, educadores, médicos e sociedade civil, é preciso evidenciar que a educação escolar só vai fazer parte, oficialmente, do espaço prisional, a partir de 1967.

A legislação penal institui como obrigatório o Ensino Fundamental e o Ensino Profissionalizante em nível de iniciação ou aperfeiçoamento para os sujeitos privados de liberdade, e o Estado do Rio de Janeiro é pioneiro no que diz respeito à oferta de educação no sistema penitenciário. 
A Cultura da Escola Prisional

Em 2005, o Centro de Políticas Sociais da Fundação Getúlio Vargas realizou uma pesquisa, denominada Retratos do Cárcere, para identificar as principais características socioeconômicas e demográficas da população que vive em penitenciárias no Rio de Janeiro e São Paulo. A pesquisa intencionava informar à sociedade civil o perfil do presidiário carioca e paulista de forma a oportunizar a organização de políticas públicas de prevenção ou de cura ligadas à violência. Os dados nos mostram as principais características desse grupo: homem, negro ou pardo, jovem, solteiro, baixa escolaridade e sem religião. Mais recentemente, de acordo com o Ministério da Justiça, projetos referentes à educação em presídios são de extrema necessidade, pois $70 \%$ da população carcerária não têm o ensino fundamental completo e só $18 \%$ dos detentos realizam algum tipo de atividade educacional no cárcere.

O interesse em um estudo sobre o cotidiano e a cultura em uma escola prisional parte do entendimento desse espaço como lugar de confrontos diários entre o instituído e o instituinte, em que não só as marcas das tecnologias disciplinares (presença de um agente nas salas de aula, obrigatoriedade no uso de uniformes e cumprimento de horários), o trabalho prescrito e as técnicas de reprodução se fazem presentes, mas também a criação, as potencialidades, as invenções diárias.

Este trabalho intenciona desvendar as transformações possíveis que se (re)desenham em um lugar, $a$ priori, marcado pelo controle, pela estaticidade, mas que, a partir de um olhar mais apurado às experiências ali vividas, permite-nos perceber o imprevisível, o movimento, a possibilidade de campo fértil; espaço acostumado a uniformização, a mortificação, visto como fecundo nas tessituras das práticas cotidianas dos sujeitos que fazem a escola da prisão.

Nossa proposta é apresentar elementos que nos permitam conceber o cotidiano e a cultura construídos na escola prisional como elementos instituintes, revoluções moleculares, produção de subjetividades que fogem das perspectivas hegemônicas, linhas de fuga; frente à reprodução do instituído, fazer interseções atentas às fixações e variações, desvendando destinos prognosticados, considerando as imprevisibilidades do fazer diário, e considerar as resistências presentes nas tentativas de disciplinamento e docilização de corpos úteis ao projeto capitalista. Buscamos, assim, contribuir para fomentar políticas públicas que melhor atendam aquele grupo e espaço diferenciado e para repensarmos e reinventarmos práticas pedagógicas que possibilitem, de maneira efetiva, a formação do cidadão crítico, autônomo e transformador do mundo em que vive.

O presente trabalho, um estudo de caso de base etnográfica, tem como objeto a primeira escola prisional fluminense, o Colégio Estadual Mário Quintana, situado na Unidade prisional Lemos Brito. A pesquisa utilizará pesquisa bibliográfica, análise documental, observação participante e entrevistas a fim de caracterizar a cultura de uma escola prisional em sua complexidade e dinamicidade. A Lemos Brito e o Colégio 
Estadual Mário Quintana sempre foram referenciados em pesquisas de diferentes áreas como um modelo a seguir, no que se refere ao tratamento do detento e às atividades ali desenvolvidas. Pretende-se compreender a construção da cultura escolar prisional a partir das práticas educativas e interações desenvolvidas na unidade escolar, atravessada pela cultura da prisão. É sabido que a preocupação maior nesse complexo de prisões é a segurança. Sendo assim, em que medida as ações constituídas nesses espaços se alteram? Como se alteram? Como se constitui a cultura escolar prisional? Como se caracteriza esse espaço de atuação?

Entendemos cultura como Geertz (1978, p. 13), em que esta é tida como uma teia de significados. Para o autor,

\begin{abstract}
[...] essa teia de significados, que é pública, pode ser interpretada quando se confere a devida importância às ações dos sujeitos, que são sempre simbólicas. A cultura não é algo ao qual podem ser atribuídos casualmente os acontecimentos sociais, os comportamentos, as instituições ou os processos, mas sim, um contexto, dentro do qual tais comportamentos, fatos, processos ou instituições podem ser descritos de forma inteligível, ou seja, com densidade (Geertz, 1978, p. 13).
\end{abstract}

Um dos que primeiro revelou a existência de uma relação íntima, orgânica entre educação e cultura foi Forquin (1997), que considera a escola como um mundo social de características e vida próprias, nomeando de cultura de escola.

Pérez Gómez (2001) ao tratar do tema identifica a escola como um espaço de cruzamento de culturas, que lhe dão identidade, relativa autonomia e a finalidade de mediar, de forma reflexiva, os múltiplos conhecimentos que chegam. O autor pensa que "[...] a escola, como qualquer outra instituição social, desenvolve e reproduz sua própria cultura específica [...]" (Pérez Gómez, 2001, p. 25), denominada cultura institucional, sendo esta definida como o conjunto de significados e comportamentos que ela cria.

Outro autor que nos ajuda a pensar a cultura escolar como objeto de pesquisa é Viñao-Frago (2000). Segundo esse autor, a categoria cultura escolar emergia como resistência a mudanças, em vista do relativo fracasso das reformas educativas, a partir das diferenças entre as culturas dos responsáveis pela elaboração dessas e a cultura dos professores, responsáveis por viver e pôr em prática essas reformas. Para ele, cultura escolar é conceituada como,

[...] conjunto de teorias, ideias, princípios, normas, pautas, rituais, inércias, hábitos e práticas - formas de fazer e pensar, mentalidades e comportamentos - sedimentados ao longo do tempo em forma de tradições, regularidades e regras do jogo não postas e que proporcionam estratégias para integração dessas instituições, para interagir 
e para dar conta, sobretudo na sala de aula, das tarefas cotidianas que de cada um se esperam, assim como para fazer frente as exigências e limitações que estão implicadas nestas tarefas. Seus traços característicos seriam a continuidade e persistência no tempo, suas institucionalizações e uma relativa autonomia que permite gerar produtos específicos - por exemplo as disciplinas escolares - que a configuram como cultura independente (Frago, 2000, p.73) como,

Segundo Julia (2001, p. 10), a cultura escolar pode ser descrita

[...] um conjunto de normas que definem conhecimentos a ensinar e condutas a inculcar, e um conjunto de práticas que permitem a transmissão desses conhecimentos e a incorporação desses comportamentos; normas e práticas coordenadas a finalidades que podem variar segundo as épocas (finalidades religiosas, sociopolíticas ou simplesmente de socialização).

Pensamos com Julia (2001) que práticas e normas são instituídas, em uma escola prisional, no processo educativo oferecido aos sujeitos privados de liberdade, tendo como objetivo a reinserção desses educandos na sociedade? Apesar de entendermos que o conceito cultura escolar não seja de simples delimitação, considera-se que a escola é um espaço de construção de normas e práticas definidoras dos conhecimentos que são ensinados e dos valores e comportamentos que se deseja inculcar, gerando o que podemos chamar de cultura escolar.

\section{A Prisão}

A instituição prisão tem como objetivos, na modernidade, a punição do sujeito desviante com a perda da liberdade, e a recuperação, através das assistências que lhe são oferecidas. Para alguns autores, como Thompson (1998), objetivos paradoxais e de difícil concretização. No espaço intramuros a cultura prisional, formal e informal, entram em choque com os valores sociais exteriores a serem apreendidos e não mais desrespeitados.

Ao falar sobre o paradoxo dos objetivos da prisão, Thompson (1998) se reporta a Donald Clemmer que caracteriza a cultura da prisão e a própria prisão como,

[...] o mundo prisional é um mundo atomizado. Seus membros são como átomos a agir reciprocamente em confusão... Não há definidos objetivos comunais. Não há um consenso comum para um fim comum. O conflito dos internos com a administração e a oposição à sociedade livre estão em degrau apenas ligeiramente superior ao conflito e oposição entre eles mesmos... É um mundo de 'Eu', 
'mim', e 'meu' antes que de 'nosso', 'seus', 'seu' (Thompson, 1998, p. 52).

Embora, seja possível perceber o detento adaptado às regras da prisão, é fato de que há o desenvolvimento, em paralelo, de uma cultura que lhe é própria, ali construída, denominada cultura informal em contraposição à cultura formal determinada pelo sistema carcerário. A cultura informal carcerária matizada pelo poder das facções, negocia com os responsáveis oficiais pela prisão. Elabora códigos e estabelece condutas; ratifica valores e promove mudanças. Enfim, o ambiente prisional apresenta-se carregado por regras e faz o indivíduo, na maioria das vezes, cooperar com esquemas coletivos, nem sempre de acordo com os caminhos que possam proporcionar a recuperação para convivência dentro dos padrões legais da sociedade extramuros.

Apesar da lógica funcional e dos ritmos próprios impostos pela instituição prisão, verifica-se a constituição de uma cultura informal estabelecida nos meandros dos processos instituídos. Os conflitos e exercícios de resistência estabelecidos no cárcere levam-nos a perceber uma estruturação social informal edificada nos limites da instituição total. O poder das facções e, mais recentemente, das milícias impõem regras, por vezes, desviantes das do poder oficial. Segui-las, no entanto, pode determinar a sobrevivência, em diversos sentidos, inclusive material, dos sujeitos na prisão, visto que nem sempre as famílias ou o Estado oferecem subsídios aos mesmos.

Caracterizada como instituição total por Goffman (2005) em que a massificação, a mortificação do eu e o tratamento homogeneizante estabelecem a lógica de seu funcionamento, a prisão intenciona o disciplinamento dos corpos e a reprodução de relações de poder instituídas pela ordem. As atividades cotidianas são submetidas a uma rígida regulamentação e padronização, a fim de contribuírem para a modificação da personalidade individual infracional.

As prisões, como projeto moderno, que deu lugar às práticas de aviltamento dos corpos em nome de penas mais humanas, têm se evidenciado como projetos fracassados, incapazes de cumprir os objetivos para que foram criadas. Em nome da Organização dos Estados Nacionais, as prisões se encarregariam de controlar e transformar àqueles que 'ameaçavam' os planos de progresso e civilidade; pois, seres sem trabalho, sem moral, sem condições de, naquele momento, participarem efetivamente do projeto de construção nacional, deveriam ser excluídos do convívio social até sua pronta recuperação.

A prisão, entre outras instituições de sequestro, como a escola, determinadas por Foucault (2005) como estabelecimentos que têm a vigilância e a disciplina como características principais, têm por finalidade "[...] fixar os indivíduos em um aparelho de normalização do homem [...]” (Foucault, 2005, p. 114). Assim, as instituições de sequestro exercem relações de poder capazes de colaborar para a produção de novas redes 
de saber e poder que favorecem a atualização das possibilidades de fabricação do sujeito moderno.

Como projeto da modernidade, à prisão interessa a transformação dos sujeitos que ali ficarão, durante um período de tempo, excluídos do grupo social, em constante vigilância, a fim de serem controlados, manipulados, adestrados, através de tecnologias disciplinares. A escola na prisão é convocada a aliar-se a esse projeto de transformação dos sujeitos, pois a ela também cabem atribuições e perspectivas transformacionais em prol de um mundo melhor e mais desenvolvido.

Embora a punição através do suplício tenha sido substituída nos discursos oficiais, a partir da instituição da pena de prisão, é fato que o sofrimento, a dor, os maus tratos e diversas perdas ainda fazem parte do cenário constituído em nossos cárceres, mesmo que de forma oficiosa, essas marcas perduram no cotidiano das prisões. Assim, o cenário necessário e ideal para o estabelecimento e concretização dos objetivos da prisão na contemporaneidade não está em consonância com o previsto em lei. A todo momento, aqueles que são excluídos para aprenderem a estar em conformidade com as leis, veem as mesmas, em relação a si próprios, serem desrespeitadas.

No Rio de Janeiro, é sabido que cada unidade prisional atende a um grupo específico: às facções, aos milicianos, aos ex-policiais que cumprem pena, àqueles que desertaram das facções ou delas foram expulsos. Às mulheres, aos menores, aos homens. Sabe-se, também, que há unidades de segurança máxima, semiabertas, custódia, cada uma com sua lógica de funcionamento. Enfim, caracterizações, vocabulários, hábitos e normas diferenciadas que influenciam diretamente na constituição da cultura prisional.

\section{A Escola}

A educação escolar, tida na contemporaneidade como elemento de formação de cidadãos críticos, reflexivos e autônomos, carrega ainda algumas marcas das tecnologias de poder e disciplina que a constituíram, a fim de conformar os sujeitos a atuarem de maneira dócil no projeto capitalista que se instituía. É fato que a educação escolar desempenha papel importante nas sociedades modernas como instrumento e espaço de socialização daqueles responsáveis pela construção de uma sociedade melhor e mais justa.

A institucionalização e difusão da educação escolar, entre a segunda metade do século XIX e início do século XX, orienta-nos a um projeto mais amplo de regeneração moral e profilaxia social, como fatores imprescindíveis à capacidade de progresso do país e civilização do corpo social, tendo a educação e o espaço escolar como aliados nessa tarefa. Como apontam Marques e Pimenta (2003), 
Assumindo diferentes contornos e incidindo sobre múltiplos aspectos, esse processo teve como uma das suas mais importantes marcas a intenção de forjar os futuros cidadãos, desdobrando-se em dispositivos civilizatórios, configurados com vistas a garantir a socialização das crianças. A difusão da escolarização não se deu sem uma intervenção sobre o corpo e a mente infantis, balizada pelo afã de produzir um conhecimento científico sobre as crianças, o qual deveria orientar a organização da instituição escolar e os procedimentos pedagógicos (Marques; Pimenta, 2003, p. 45-49).

Perceber as potencialidades que engendram a escola não parece tarefa fácil, visto que, segundo Rocha (2004), esta tem sido entendida como uma instituição capaz de produzir e ser produzida consonante a uma lógica homogeneizante, que favorece, então, "a subjetividade mecânica através de cada elemento da comunidade, de cada signo, símbolo ou regra que a atualiza, revigorando-se enquanto fábrica de socialização padronizada" (p. 186). É fato também que os movimentos disruptores das práticas instituídas tendem, em algumas situações, a tornarem-se padrões, a serem reproduzidos e seguidos. Sendo assim, é preciso entender a lógica dos movimentos que permeiam o fazer escolar como elementos processuais, em que não há vencidos ou vencedores eternos.

À escola, têm sido atribuídas falhas e injustiças, possibilidades e vigor. De acordo com Dubet (1998), até que ponto seria a escola justa, já que a cultura escolar transmitida por ela seria aquela imposta e legitimada pelas classes dominantes, fato esse que leva a escola a ser vista como reprodutora das desigualdades sociais, conforme atestaram Bourdieu e Passeron (1975), pois trata de forma igual aos que são diferentes. É sabido que a escola na prisão funciona como dispositivo legal no projeto de recuperação daqueles que, por conta de algum comportamento desviante, pagam sua dívida com a sociedade; dá-se, assim, a exclusão do meio social para a possibilidade de inclusão, dentro dos padrões legais exigidos. No entanto, faz-se mister lembrar um dos caracterizadores do perfil dos detentos brasileiros: a baixa escolaridade. Ou seja, extramuros, a escola não cumpriu com a maioria dos apenados seu objetivo de formação do cidadão, de garantia de certificação capaz de permitir a entrada no mercado de trabalho, de compartilhamento com as regras de convivência do grupo social. A escola justa não é uma realidade para esse grupo. Sendo assim, a escola na prisão precisa constituir-se de maneira diferenciada da escola excludente já conhecida por muitos. E como analisar, entender esse espaço de fracassos e fracassados em suas potencialidades e não apenas em sua reprodutibilidade? A construção da memória e da cultura daquele espaço nos parece um caminho profícuo a trilhar por essa seara.

O espaço escolar pode ser entendido nas sociedades contemporâneas como lugar de combate a atitudes discriminatórias e excludentes; 
em que os diferentes, os estrangeiros, enfim, os considerados anormais de todo tipo podem conviver e participar na construção de uma sociedade inclusiva. No entanto, essa mesma escola, de certa maneira, tem forjado o indivíduo que participa e alimenta o modelo econômico e político produtor da exclusão, contribuindo assim para a dificuldade de concretização de uma escola mais justa na formação de uma sociedade menos desigual. Encontramos aí um paradoxo, estabelecido nas escolas extramuros que, porém, tende a intensificar seus efeitos nas escolas situadas no cárcere. Cientes do risco de cair na ilusão, como afirma Adorno (2003), de uma sociedade que se organiza em torno da aparência de liberdade, procuramos utilizar outras lentes que intensifiquem o olhar local, sem, porém, perder de vista o contexto global, também determinante na configuração do espaço escolar prisional e de suas práticas.

Embora políticas educacionais forjadas em gabinetes, práticas educacionais utilitárias e conformadoras, ritualizações do cotidiano enviesem o espaço escolar, acreditamos que exercícios de resistência irrompam em meio a esses processos, dando visibilidade aos fazeres cotidianos e a um caminho que ressalta os movimentos instituintes. Não se trata aqui de reconhecer apenas a potencialidade do micro, das práticas cotidianas, mas sim de lançar luz na dinâmica que se estabelece entre o contexto macro, as prescrições, o instituído e outras possibilidades que se anunciam na constituição das práticas escolares diárias. Configurar um mosaico em que tempos e espaços, sujeitos e normas, passado e presente trocam e se tocam rumo à construção de outras paisagens possíveis.

Ao mergulhar no cotidiano escolar como forma de perceber a cultura ali constituída, intenciona-se destacar as possibilidades de criação no tempo e espaço escolares, indo além das assertivas que engessam a escola e seus sujeitos em discursos de sucateamento e desânimo.

Rocha (2004) apresenta-nos dados, a partir da configuração escolar, que ratificam os dispositivos que pedagogizam as relações e o conhecimento produzidos na escola como responsáveis pelo tédio ali vivido, capaz de permitir a paralisia e cegueira de muitos ao que pulsa a seu redor. Segundo a autora,

[...] à medida que é por meio de sucessivas divisões e naturalizações do processo que se atualiza a lógica que exclui a diferença. Pedagogizar implica dar forma às ações, às situações, tendo como referência os modelos, os padrões convencionais, aceitos socialmente como normais. No que tange ao conhecimento, a pedagogização atua produzindo/reproduzindo divisões e hierarquizações que naturalizam os saberes. Esses saberes deixam de ser datados e implicados com circunstâncias, para se constituírem em verdades universais (Rocha, 2004, p. 187).

Assim, a educação escolar, padroniza comportamentos: certo e errado, bom e mau; a lógica dominante se evidencia; o diferente é exclu- 
ído, inclusive o professor em relação a seu saber construído nas práticas cotidianas. Não se trata aqui de destacar o caráter redentor das práticas cotidianas e das interações entre os sujeitos no tempo e espaço escolar, mas sim de reconhecer nas ações realizadas no micro e nas construções que ali se dão, vontade de poder. Ao destacarmos que as prescrições não dão conta da variabilidade das situações de trabalho, a escola é aqui entendida como lugar de criação, de vida. Compactuamos com Nietzsche (2002) quando atesta que vida é vontade, vontade de poder. Assim, se vontade é vida, ela deve ser afirmada e não negada. Para o autor, a vida quer sempre expandir e nunca estagnar. A compreensão de cotidiano, aqui colocada, remete-nos a um campo de forças em luta, e não simplesmente como espaço de mera reprodução de práticas naturalizadas. O cotidiano pode nos oferecer diferentes modos de existência e possibilitar a tessitura de movimentos instituintes capazes de afastarem ou minimizarem práticas excludentes.

Os processos de subjetividade são constituídos por meio de complexos processos de interação social, cujos resultados não podem ser previstos apenas pelo conhecimento dos sujeitos a respeito de suas posições nas estruturas sociais, mas podem ser melhores entendidos com o conhecimento do exercício das atividades cotidianas, com a observação dos diversos eventos mais ou menos imprevisíveis de que participam e com a observação dos modos de se relacionar com o espaço escolar e com o saber. Na tentativa de captar movimentos de resistência, engendradas em propostas institucionalizadas, mas possíveis de serem reconhecidas nos imprevisíveis da atividade.

Sabe-se que subjazem no espaço escolar relações de poder, mas que o poder não é localizável, e sim relacional; o poder circula e funciona em cadeia. Ao se exercer o poder, incidindo ação sobre ação e não mera dominação colocam-se em circulação práticas de saber, necessárias ao exercício de poder.

Em Foucault (2006), destaca-se também a noção de resistência como elemento inerente às relações de poder, incitando seu exercício. Segundo esse autor, o próprio poder é efeito de um conjunto de práticas, de relações de forças, agindo uma sobre as outras, sem estar localizado ou totalizado em um indivíduo. Compactuando com Foucault, Heckert (2004), sobre as relações de poder, diz-nos que:

[...] pulverizadas no campo social, as relações de poder
são positivas e criadoras; não quer dizer com isso que
tudo seja relação de poder e que há um poder que tudo
domina. A intenção do filósofo, no entanto, foi escapar de
uma caracterização do poder como apenas submissão ou
dominação (Heckert, 2004, p. 56).

Para ele, o poder se exerce em rede e, nessa rede, não só os indivíduos circulam, mas estes estão sempre em posição tanto de serem submetidos a esse poder como também de exercê-lo. Jamais eles são alvo 
inerte ou consentido do poder, são sempre seus intermediários (Foucault, 2005).

Assim, mesmo que as políticas oficiais determinem e as prescrições delimitem as ações dos sujeitos, é fato que os saberes da experiência, as contingências da vida e tantos outros conhecimentos não hierarquizados e contemplados oficialmente, invadem e se mesclam aos fazeres diários, propiciando novas configurações ao espaço escolar.

Interessa-nos entender de que modo operam as relações de poder, forças em exercício, e resistências na escola prisional, compreendendo as táticas e estratégias utilizadas pelos sujeitos praticantes desse espaço, podendo assim entender os modos de constituição dos sujeitos. O foco do estudo nas práticas cotidianas para a construção da cultura escolar mostra-se fecundo para um melhor entendimento das relações de poder que definirão que cultura escolar aí se constitui, pois, segundo Heckert (2004), ao analisar as relações de poder tendo como referencial Foucault , aponta-nos que

[...] o estudo do poder deveria se concentrar nas práticas efetivas, apreendendo seu engendramento nas táticas e estratégias anônimas. Ou seja, perscrutá-lo no campo onde as ações produzem práticas que regulam condutas e reafirmam processos de sujeição, captando, portanto, a dimensão material dos processos de sujeição (Heckert, 2004, p. 53).

Segundo Rocha (2004), a escola tem sido reconhecida como espaço de socialização, de constituição legalizada do sujeito na sociedade e responsável pelo reconhecimento da constituição do cidadão produtivo. Sendo assim, é compreensível a educação escolarizada aparecer como uma das assistências oferecidas como direito ao preso na Lei de Execução Penal. Mesmo com o reconhecimento da importância do espaço escolar no imaginário social, é preciso pensar a escola e as práticas que ali se efetivam também pelas brechas do instituído, pois o sistema não existe sem conflitos, fraturas, resistências. Mesmo partindo de pontos pessimistas que imputam à escola a inércia, a reprodução, o sucateamento, o desânimo, com seus métodos homogeneizantes e burocráticos na organização do tempo-espaço, não se pode silenciar a potência instituinte que permeia as ações cotidianas escolares. Há sempre terrenos porosos e abertos, suscetíveis de movimento.

Do mesmo modo que o poder, as forças de resistência, segundo Foucault (2006), não têm poder absoluto. Sabe-se que a prisão e a escola como instituições disciplinadoras também apresentam imposições e brechas, determinações e possibilidades, relações de poder e forças de resistência coexistindo em um processo dialético e pulsante.

No exercício de entendimento das significações construídas no cotidiano escolar, estabelece-se também a articulação entre as relações dos sujeitos com os diversos saberes, visto que essa relação será primor-

104 Educação \& Realidade, Porto Alegre, v. 38, n. 1, p. 93-112, jan./mar. 2013. Disponível em: <http://www.ufrgs.br/edu_realidade> 
dial para a definição dos papéis mobilizados pelos sujeitos no processo educativo e que podem definir também seu lugar no social. Essas práticas de socializações e relações com o saber conduzem os sujeitos da educação a poder jogar o jogo nos campos de lutas das relações sociais, mas também podem torná-los subjetivados contra a escola, como nos informa Dubet (1998). O cotidiano escolar, atravessado por crenças e valores, e, assim como as ações humanas construídas historicamente, estabelecedor de relações com o mundo em suas interações marcadas por constantes conflitos, aponta-nos um horizonte a desvendar.

Os estudos sobre a cultura escolar, suas práticas e sujeitos, emergem, a partir da década de 1980, como uma nova forma de perceber a escola no seu dia-a-dia, evidenciando o plano molecular, e de buscar outras possibilidades para esse espaço além da reprodução e do tédio.

Além de atestar a crise da escola, estudiosos apontam um olhar voltado para dentro da escola como possibilidade de um melhor entendimento de seu funcionamento. Como propôs Azanha (1991) é preciso "[...] realizar um mapeamento cultural da escola, atento à sua constituição histórico-social [...]” (p. 37), já que era no interior desta que as resistências ou adesões às reformas se davam. Na década de 90 , do século $\mathrm{XX}$, os estudos, tendo como objeto de análise a cultura escolar, intensificam-se, tornam-se ainda mais profícuos e advém de diversas áreas do conhecimento.

Assim, entendemos que os estudos e pesquisas sobre a cultura escolar podem nos direcionar a um outro olhar sobre a escola, principalmente, sobre a escola na prisão, tão carregada de estigmas e de processos de rotinização, efeitos de contaminação da cultura prisional. Poder-se-á, então, indagar se a escola não se apresenta como um lugar de criação e não apenas reprodução, mesmo aquela condicionada às normas de segurança. Ao invés de buscar a reprodução ou só a criação, é possível, através da percepção sobre a cultura escolar um reconhecimento desses movimentos diversos e alternados; é possível entendêlos em sua dinamicidade e diálogo, transitando entre normas e teorias, práticas e interações, instituído e instituinte. É o interior da escola um espaço de lutas, conflitos, dinamismo, produção; mesmo quando o instituído se faz presente nas ações diárias.

As atividades cotidianas realizadas em uma escola na prisão apresentam-se carregadas pelo imprevisível, pois, mesmo que ações sejam planejadas e o prescrito determinado, não é possível a execução fidedigna das prescrições durante o desempenho das atividades humanas, principalmente, em um ambiente em que se confrontam as determinações da escola, com suas preocupações pedagógicas a dar conta e as da prisão, em que as questões de segurança se sobrepõem. É saber que o espaço vivido, (contraditório, às vezes opaco, outras brilhante, garantidor da dialética e da contradição) não é o espaço pensado em gabinetes, ainda mais quando pensado por estruturas diferenciadas e com objetivos - educação e segurança, aparentemente comuns, mas 
nem sempre praticados para o mesmo fim. A valorização do que é ordinário, no sentido stricto do vocábulo, evidencia a tentativa de fazer do espaço-ambiente possibilidade e não apenas limite.

A educação na prisão pode se caracterizar como uma educação transformadora ao evidenciarmos a criação e as interações cotidianas como elementos constituintes do processo formativo e instituintes ao interrogar o já estabelecido e instituído que circula no cotidiano de nossas escolas. Os encontros fortuitos e diários no espaço escolar vão instituindo um eu sempre pronto a se reinventar, em que o processo de se tornar não se conclui ou estanca. É sempre movimento que não cessa de acontecer; é sempre efeito provisório e contingente de forças em ação. Segundo Rocha (2004, p. 49), "o homem se constitui no tempo, pelo encontro com outros efeitos, pela ação das circunstâncias que vêm ao seu encontro. Mas o verbo constituir-se é aqui excessivo: porque justamente ele não está jamais constituído".

Deste modo, as atividades diárias devem ser consideradas e valorizadas, pois permitem o encontro com as experiências, em que o diferente muitas vezes está presente; permite-nos transformar e ser transformados, no embate constante com as circunstâncias. A transformação implica perceber certo espaço do não saber, em que saberes podem ser constituídos em meio à experiência, numa dinâmica entre instituídoinstituinte que não cessa, nem pressupõe vencedores ou vencidos. Não se trata de simplesmente negar a educação em sua vertente de formação do cidadão, da cultura a ser transmitida de geração a geração ou, como nos aponta Hannah Arendt (1979), de perceber que educação é por natureza conservadora. Instiga-nos, porém, enxergar além do fato dado, estabelecido e buscar nos meandros dos fazeres diários, desses sujeitos que se reinventam cotidianamente, uma possibilidade de educação capaz de lidar com o contingente, com a inconstância de processos e procedimentos, em um espaço diferenciado como a escola no cárcere, em que formação e transformação não se contradizem ou excluem, mas convivem, interagem, dialogam.

Embora os estudiosos da cultura escolar apresentem algumas especificidades em relação ao entendimento sobre tal objeto, é certo que percebem essa categoria como elemento determinante para outro entendimento sobre o espaço-tempo escolares e as práticas que lá se efetivam. Descontinuidade, caos, desejo, rupturas, criatividade frente às prescrições são palavras de ordem nesse estudo.

A cultura de uma escola prisional construída no entre da cultura escolar extramuros e da cultura formal e informal constituída na prisão, propicia aos sujeitos, que ali interagem, o tornar-se em processo contínuo, simplesmente movimento, devir, indo além da realização de modelos normativos.

Ao afirmar que não há forma perfeita ou ideal a se alcançar, Nietzsche (1995) nos remete ao espaço escolar em que sujeitos vão se construindo no caminhar, mesmo que nesse caminho haja medo, incerteza,

106 Educação \& Realidade, Porto Alegre, v. 38, n. 1, p. 93-112, jan./mar. 2013. Disponível em: <http://www.ufrgs.br/edu_realidade> 
dúvidas. Entendendo a escola como espaço relacional em que as possibilidades, subjetividades, ferramentas podem, muitas vezes, serem criadas no cotidiano escolar, a partir de linhas de fuga, entendida aqui como ação e não rejeição ou fim, que surgem como alternativas ao instituído. Por mais que as forças da cultura escolar e prisional se façam presentes, características próprias criadas, recriadas, retomadas, contraídas e em movimento se expandem por todo espaço, em que novos modos de experimentação da atividade são criadas na vivência cotidiana. O espaço escolar prisional, aparentemente uniformizado, leva-nos a, quem sabe, reconhecer a significância de elementos anteriormente invisíveis, até mesmo durante a reprodução de procedimentos e fazeres.

\section{A Cultura da Escola na Prisão}

Nesse tópico, abordar-se-ão alguns indicativos do estudo em questão, considerados centrais. O primeiro destaque a fazer é em relação às caracterizações e às condições de trabalho na escola estadual Mário Quintana, assim como em relação aos atores que estudam, pesquisam e vivem a prisão, a escola e a educação prisional. Houve alguns fios que perpassaram a fala de todos os entrevistados até agora, quando se falou da função da prisão e da educação na prisão: a prisão como instrumento eficaz e eficiente do sistema capitalista, a ideia de ressocialização como uma falácia contemporânea e a educação prisional como elemento para redução de danos da vida na prisão.

O Colégio Estadual Mário Quintana localiza-se em uma prisão de segurança máxima, a Lemos Brito, e apresenta a seguinte estrutura: no pavilhão A, onde estão presos os ex-policiais, bombeiros e vagabundos (designação dada pelos ex-policiais aos presos que nunca usaram farda, os presos comuns) a maioria já tem um relevante grau de instrução. Muitos já haviam ingressado até em universidades, pois os chamados milicianos são servidores públicos. Sendo assim, apresentam maior escolarização do que a maioria dos presos ditos comuns. Desta forma, percebe-se que o que os levou a condição de preso não foi a falta de escolaridade. Esses, no entanto, ainda são minoria no sistema.

A massa carcerária, segundo dados anteriormente apresentados, tem baixa escolaridade. Apesar disso, a escola não perde a sua importância no sistema carcerário para esse grupo. Além de atender aos alunos que não tiveram a oportunidade de concluir ou, simplesmente, de ingressar na Educação Básica, a escola é uma maneira de ocupar positivamente a cabeça dos presos, dando novos horizontes, novas perspectivas e novas possibilidades. Interessante constatar que a biblioteca da escola está estabelecida no lado A.

No pavilhão B, onde estão os presos da facção Terceiro Comando, o grau de escolaridade é bem menor. A maioria dos alunos está nos primeiros anos do Ensino Fundamental. Isso evidencia, por um lado, a necessidade da construção de uma educação prisional e de uma cultu- 
ra escolar prisional, diferentes das existentes nas escolas extramuros, que atenda as especificidades do espaço e do grupo. A cadeia é criada para ser burocrática e espaço de opressão; assim, a escola deve estar na contramão da cadeia: tem que criar contradições. A cultura escolar prisional precisa fugir à lógica da certificação e do passar de ano. É preciso constituir-se como projeto pedagógico de compreensão de mundo, para que os sujeitos ali presos possam entender que o papel deles no mundo pode ser outro além daquele. Deste modo, podem-se transformar discursos tais como os colhidos durante as entrevistas em que dois alunos do pavilhão B, quando perguntados se sairiam do tráfico, responderam que não. Um disse que se saísse ele poderia morrer, porque nessa vida de faz muitos inimigos e saindo do crime, ele não teria como se defender e o outro disse que tinha que ver como ia estar o tráfico quando ele saísse, se tivesse tranquilo ele voltaria, não demonstrando nenhuma vontade, mesmo que momentânea de deixar o crime. No pavilhão A, um aluno disse que o que ele não faria mais era matar porque homicídio dá muita cadeia, mas que continuaria com outras coisas mais simples, porém ilegais, ilícitas. A partir daí, podemos perceber que o objetivo de ressocialização esperado com a pena de privação de liberdade depende de muitos elementos, para que se efetive, além da escola, inclusive da percepção do grupo social em relação às fortes contradições sociais que nos cercam. Não se trata de entender a sociedade como em equilíbrio e os erros como individuais, pois será mera coincidência o perfil da população carcerária, anteriormente descrito?

A cultura escolar prisional pode refletir a produção e fortalecimento das subjetividades hegemônicas, a partir da reprodução dos valores dominantes, normatizados, ou produzir singularizações, levando o sujeito a pensar que existem outros modos de estar no mundo. As discussões da comunidade escolar, inclusive com a ouvidoria dos alunos, sobre o currículo e o projeto político pedagógico das escolas prisionais se apresentam como formas instituintes presenciadas, durante a pesquisa, no Colégio Estadual Mário Quintana, e modos de singularizações frente ao instituído.

A cultura prisional, que atravessa a construção da cultura escolar naquele espaço, atende a lógica da segregação prisional por facções e pode ser entendida como um reforço na identidade de criminoso; identidade essa que a prisão e a educação carcerária deveriam imbuir-se de transformar, afastar. A educação na prisão é uma das únicas possibilidades de dar dignidade a essas pessoas, de gerar alteridade, de permitir a construção de identidades distintas e distantes das organizações criminosas que se perpetuam em nossas cadeias.

Caracterizar a escola na prisão parece necessário para percebermos a importância das lógicas de funcionamento e práticas desse espaço. A escola na prisão atende a localizações diferenciadas dentro das unidades prisionais: umas são no miolo da cadeia (é preciso percorrer toda a cadeia para se chegar à escola); outras, fora da unidade. A maio-

108 Educação \& Realidade, Porto Alegre, v. 38, n. 1, p. 93-112, jan./mar. 2013. Disponível em: <http://www.ufrgs.br/edu_realidade> 
ria dos espaços destinados às escolas no cárcere são improvisados, nem sempre tendo sido desenvolvidos, projetados, construídos especificamente para esse fim. As salas são pequenas e muitas utilizam divisórias (que não vão até o teto) para separar as salas. Os espaços são pequenos e limitadores, para alunos e professores. A escola funciona concomitantemente com os horários de visitas dos presos, o que por vezes os leva a faltar. A rotatividade dos alunos é grande, principalmente nas unidades de custódia e de regime semiaberto; a falta de capacitação de agentes e professores é um problema constante; a impossibilidade de utilização de determinados materiais um empecilho.

Foi possível perceber que o corpo docente do Colégio Estadual Mário Quintana, ressente-se de uma maior integração entre o saber acadêmico e o saber da experiência nos projetos elaborados pela Secretaria de Educação, relacionados ao cotidiano das escolas prisionais. Para eles, tem-se teorizado muito sobre o assunto e quem teoriza não conhece a realidade das escolas no sistema prisional ou, se conhece, não lança mão desse saber. Muito se exige dos professores: são metas, prazos. As mesmas cobranças feitas às escolas de fora do sistema prisional são feitas a eles. Questiona-se: como fazer mais se as condições se apresentam tão desfavoráveis à prática pedagógica. A lógica experimentada parece ser a prisão como espaço de controle de ilegalidades populares e como elemento de criminalização dos pobres. É importante destacar em que medida e sob que ótica atestamos estar a prisão em crise? Entendemos que a prisão é uma lógica fracassada na visão humanística, mas na perspectiva da detenção da pobreza e na lógica da repressão de segurança, funciona muito bem. Na lógica do sistema capitalista, a improdutividade tem sua utilidade.

Muitos alunos veem a escola como uma maneira prática e rápida de conseguir remissão de pena. Além disso, muitos deles se dedicam aos estudos, não por perceber a sua importância, mas por algum tipo de simpatia desenvolvida em relação aos professores, pela possibilidade de interações diferenciadas, pela diminuição do ócio infligido pelo cárcere. Em meio aquele mundo paralelo, a escola se torna um oásis, um refúgio e um local de reuniões, onde os alunos podem se encontrar e conversar sobre seus processos, benefícios e planos, pois é um espaço comum a todas as galerias.

Embora o Estado se proponha, com a pena de prisão, a diversas funções, é inerente à cultura prisional o castigo e o sofrimento. Os objetivos prometidos desde a fundação da prisão nunca foram alcançados. Pelo contrário, a prisão tem aprofundado estereótipos e reproduzido as desigualdades que encontramos fora da prisão, com mais violência. Basta observarmos o perfil, o número de encarcerados e a participação desses nas atividades (quando) oferecidas no cárcere. Durante a pesquisa, corroboramos com a ideia de que algumas restrições devem ser feitas, visando à segurança de todos, mas em muitos casos, percebemos que essas restrições acontecem com o objetivo de tolher/ minar inicia- 
tivas que possam beneficiar os presos. Uma dessas iniciativas são as atividades pedagógicas desenvolvidas pela escola. Muitas vezes, ouve-se, pelos corredores, de agentes da própria escola que estamos na casa dos outros [...] e por isso não temos liberdade de trabalhar como queremos, temos que pedir autorizações, permissões, consentimento. Isso restringe a prática pedagógica.

Os estudos sobre a cultura de uma escola prisional propõem a existência de uma cultura própria da instituição, que torna a escola singular e nos faz mergulhar em seu cotidiano na intenção de dar significado a modos aparentemente invisíveis vividos no espaço-tempo escolar. Entendemos que as práticas cotidianas de uma escola na prisão podem revelar novas possibilidades do fazer escolar que garantam um novo olhar sobre a escola e seus sujeitos, além do previsto pelas políticas oficiais. Nesse movimento entre o prescrito e o real, o instituinte emerge e confronta o instituído e novos modos de produção de subjetividades engendram o espaço escolar prisional tido como lugar de homogeneização. Momento esse, que a cultura prisional permite a sobreposição da cultura da escola da prisão, marcada pelas práxis de seus sujeitos. Compactuamos com Certeau (2009), para quem

[...] o cotidiano é aquilo que nos é dado cada dia (ou que nos cabe em partilha), nos pressiona dia após dia, nos oprime, pois existe uma opressão do presente. Todo dia, pela manhã, aquilo que assumimos, ao despertar, é o peso da vida, a dificuldade de viver, ou de viver nesta ou noutra condição, com esta fadiga, com este desejo. O cotidiano é aquilo que nos prende intimamente, a partir do interior. É uma história a meio de nós mesmos, quase em retirada, às vezes velada. [...] O que interessa ao historiador do cotidiano é o invisível (Certeau, 2009, p. 31).

Interrogarmo-nos sobre o uso de uma lógica diferenciada, a lógica da prática, indo além daquela que ratifica a classificação, a hierarquização, em um constante movimento de elos constitutivos, que nos façam compreender como recomeçar, recriar, ressignificar e explorar os fazeres repetitivos.

Entender como esta relação entre cultura(s) e educação carcerária acontecem no cotidiano escolar favorece a construção de novos fazeres na escola da prisão que contribuam, de maneira mais efetiva, para a inclusão dos sujeitos privados de liberdade no meio social.

O desafio está lançado, pois procuramos entender um processo de recuperação, através da educação, que exclui para incluir. Procuramos escapar da lógica da falência do sistema prisional, da força das culturas da prisão, construindo, no espaço escolar, caminhos profícuos para a realização de debates entre os diferentes saberes, conhecimentos, culturas e valores ali produzidos, experienciados, constituindo ações que promovam a reflexão, a análise crítica, o diálogo plural entre os diferentes, valorizando-os em suas singularidades.

110 Educação \& Realidade, Porto Alegre, v. 38, n. 1, p. 93-112, jan./mar. 2013. Disponível em: <http://www.ufrgs.br/edu_realidade> 


\section{Notas}

1 Lei de Execução Penal (LEP) - A Lei de Execução Penal n 7.210 de 1984 (LEP) representou um avanço na legislação, quando criada, já que passou a reconhecer o respeito aos direitos dos presos, prevendo, então, tratamento individualizado.

2 Instituto Brasileiro de Geografia e Estatística. Disponível em:<http://www.ibge. gov.br/home/estatistica/populacao/censo2010/caracteristicas_da_populacao/ tabelas_pdf/ttal.pdf>. Acesso em: 12 maio 2012.

\section{Referências}

ADORNO, Theodor L. W. Educação e Emancipação. 3 ed. São Paulo: Paz e Terra, 2003.

APENAS 8,3\% dos Presos Participam de Alguma Atividade Educacional Segundo Ministério. Site Rede Brasil Atual. 21 set. 2011. Disponível em: <http://www. redebrasilatual.com.br/temas/cidadania/2011/09/apenas-8-3-dos-presos-participam-de-alguma-atividade-educacional-segundo-ministerio $>$. Acesso em: 10 jun. 2012.

ARENDT, Hannah. A Crise na Educação. In: ARENDT, Hannah. Entre o Passado e o Futuro. São Paulo: Perspectiva, 1979, (Debates. Política; v. 64). P. 221-247.

AZANHA, José Mário Pires. Cultura Escolar Brasileira. Revista USP, São Paulo, n. 8, p. 37-40, dez./jan./fev. 1991.

BOURDIEU, Pierre; PASSERON, Jean-Claude. A Reprodução. Elementos para uma teoria do sistema de ensino. Rio de Janeiro: Francisco Alves, 1975.

BRASIL. Lei n. 7.210, de 11 de julho de 1984. Institui a Lei de Execução Penal. Diário de Oficial [da] República Federativa do Brasil, Brasília, DF, 13 jul. 1984. Disponível em: <http://www.planalto.gov.br/ccivil_03/leis/L7210.htm>. Acesso em: 29 nov. 2012

BRASIL. Lei n. 12.433, de 29 de junho de 2011. Altera a Lei n. 7.210, de 11 de julho de 1984 (Lei de Execução Penal), para dispor sobre a remição de parte do tempo de execução da pena por estudo ou por trabalho. Diário de Oficial [da] República Federativa do Brasil, Brasília, DF, 30 jun. 2011. Disponível em: <http://www. planalto.gov.br/ccivil_03/_ato2011-2014/2011/lei/112433.htm>. Acesso em: 29 nov. 2012.

CERTEAU, Michel de. A Invenção do Cotidiano: a arte de fazer. São Paulo; Vozes, 2009. V. 1.

DUBET, François. A Formação dos Indivíduos: a desinstitucionalização. Revista Contemporaneidade e Educação, v. 3, n. 3, p. 27-33, 1998.

FORQUIN, Jean-Claude. Escola e Cultura: as bases sociais e epistemológicas do conhecimento escolar. Porto Alegre, Artes Médicas, 1993.

FOUCAULT, Michel. Microfísica do Poder. Rio de Janeiro: Edições Graal, 2006. FOUCAULT, Michel.Vigiar e Punir. História da violência nas prisões. Rio de Janeiro: Vozes Editora, 2005. 
GEERTZ, Cliford. A Interpretação das Culturas. Rio de Janeiro, LTC, 1978. GOFFMAN, Erving. Manicômios, Prisões e Conventos. São Paulo: Perspectiva, 2005.

HERCKERT, Ana Lucia Coelho. Narrativas de Resistências: obtenção e políticas. 2004. Tese (Doutorado em Educação) - Programa de Pós-Graduação em Educação, Faculdade de Educação, Universidade Federal Fluminense, Niterói, 2004.

JULIA, Dominique. A Cultura Escolar como Objeto Histórico. Revista Brasileira de História da Educação, n. 1, p. 09-43, Campinas, 2001.

MARQUES, Vera Regina Beltrão; PIMENTA, Heloisa Helena. A Produção do Aluno Higienizado. In: CONGRESSO LUSO-BRASILEIRO DE HISTÓRIA DA EDUCAÇÃO: percursos e desafios da pesquisa e do ensino de história da educação, 4., 2006, Uberlândia. Anais... Uberlândia: UFU, 2006. Disponível em: <http:// www.faced.ufu.br/colubhe06/anais/arquivos/416HeloisaHelenaPimentaRoch a_e_VeraReginaMarques.pdf > . Acesso em: 25 mar. 2012.

NIETZCHE, Friedrich. Ecce Homo: como alguém se torna o que é. Tradução, notas e posfácio: Paulo César de Souza. 2. ed. São Paulo: Companhia das Letras, 1995.

NIETZCHE, Friedrich . Genealogia da Moral: uma polêmica. Tradução: Paulo César de Souza. São Paulo: Cia. das Letras, 2002.

RELATORIA Nacional para o Direito Humano à Educação. 2009. Educação nas Prisões Brasileiras. Plataforma DhESCA. Disponível em: <http://www. dhescbrasil.org.br/attachments/289_Educa\%C3\%A7\%C3\%A3o\%20nas\%20 pris\%C3\%B5es\%20do\%20Brasil.pdf>. Acesso em: 10 maio 2012.

ROCHA, Silvia Pimenta Veloso. Tornar-se quem se é: educação como formação, educação como transformação. In: PINHEIRO, Paulo; FEITOSA, Charles; BARRENECHEA, Miguel Angel de (Org.). Nietzsche e os Gregos: Arte, Memória e Educação. DP\&A, 2004. P. 49.

SISTEMA Penitenciário no Brasil, 2008. Disponível em: <http://portal.mj.gov. $\mathrm{br} / \mathrm{main}$.asp?View $=\{$ D574E9CE-3C7D-437A-A5B6-22166AD2E896 $\} \&$ BrowserTy pe $=I E \& L a n g I D=p t \quad$ br\&params $=$ itemID\%3D $\{598 A 21 D 8-92 E 4-44 B 5-943 A-0 A E$ E5DB94226 $\} \% 3 B \& U I P a r t U I D=\{2868 B A 3 C-1 C 72-4347-B E 11-A 26 F 70 F 4 C B 26\}>$. Acesso em: 12 abr. 2011.

THOMPSON, Augusto. A Questão Penitenciária. 4. ed. Rio de Janeiro, Forense, 1998.

VIÑAO FRAGO, Antonio; ESCOLANO, Augustin. Currículo, Espaço e Subjetividade: a arquitetura como programa. Rio de Janeiro: DP\&A, 2000.

Elizabeth de Lima Gil Vieira é doutoranda em Memória Social pela UNIRIO, em Rio de Janeiro/ Rio de Janeiro. Professora da Universidade Moacyr Sereder Bastos. Atua nos temas: educação de jovens e adultos em situação de privação de liberdade, prática de ensino. País: Brasil - Rio de Janeiro/RJ. E-mail: bethlimagil@hotmail.com 